\title{
Antioxidant, Antinociceptive, and Anti-Inflammatory Effects of Carotenoids Extracted from Dried Pepper (Capsicum annuum L.)
}

\author{
Marcela Hernández-Ortega, ${ }^{1}$ Alicia Ortiz-Moreno, ${ }^{1}$ \\ María Dolores Hernández-Navarro, ${ }^{2}$ Germán Chamorro-Cevallos, ${ }^{3}$ \\ Lidia Dorantes-Alvarez, ${ }^{1}$ and Hugo Necoechea-Mondragón ${ }^{4}$ \\ ${ }^{1}$ Departamento de Ingeniería Bioquímica, Escuela Nacional de Ciencias Biológicas, Instituto Politécnico Nacional, \\ Plan de Ayala y Carpio s/n, 11340 Mexico City, DF, Mexico \\ ${ }^{2}$ Departamento de Farmacia, Facultad de Química, Universidad Autónoma del Estado de México, Paseo Colón Esquina Paseo Tollocan, \\ 50120 Toluca, MEX, Mexico \\ ${ }^{3}$ Departamento de Farmacia, Escuela Nacional de Ciencias Biológicas, Instituto Politécnico Nacional, Avenida Wilfrido Massieu s/n, \\ Esquina Manuel L. Stampa, 07738 Mexico City, DF, Mexico \\ ${ }^{4}$ División Coordinación de Operación de Redes de Investigación, Edificio Secretaría Académica, Instituto Politécnico Nacional, \\ Avenida Miguel Othón de Mendizábal s/n, 07738 Mexico City, DF, Mexico
}

Correspondence should be addressed to Alicia Ortiz-Moreno, ortizalicia@hotmail.com

Received 6 July 2012; Accepted 21 August 2012

Academic Editor: Anton M. Jetten

Copyright (c) 2012 Marcela Hernández-Ortega et al. This is an open access article distributed under the Creative Commons Attribution License, which permits unrestricted use, distribution, and reproduction in any medium, provided the original work is properly cited.

Carotenoids extracted from dried peppers were evaluated for their antioxidant, analgesic, and anti-inflammatory activities. Peppers had a substantial carotenoid content: guajillo $3406 \pm 4 \mu \mathrm{g} / \mathrm{g}$, pasilla $2933 \pm 1 \mu \mathrm{g} / \mathrm{g}$, and ancho $1437 \pm 6 \mu \mathrm{g} / \mathrm{g}$ of sample in dry weight basis. A complex mixture of carotenoids was discovered in each pepper extract. The TLC analysis revealed the presence of chlorophylls in the pigment extract from pasilla and ancho peppers. Guajillo pepper carotenoid extracts exhibited good antioxidant activity and had the best scavenging capacity for the $\mathrm{DPPH}^{+}$cation $(24.2 \%)$. They also exhibited significant peripheral analgesic activity at 5,20, and $80 \mathrm{mg} / \mathrm{kg}$ and induced central analgesia at $80 \mathrm{mg} / \mathrm{kg}$. The results suggest that the carotenoids in dried guajillo peppers have significant analgesic and anti-inflammatory benefits and could be useful for pain and inflammation relief.

\section{Introduction}

Recently, fruits and vegetables have been recognized as natural sources of various bioactive compounds [1-3]. The main phytochemical compounds present in fruits and vegetables are flavonoids, anthocyanins, vitamins $\mathrm{C}$ and $\mathrm{E}$, phenolic compounds, dietary fiber, and carotenoids [4]. A lower risk of developing various chronic diseases has been attributed to these phytochemicals, in particular to their antioxidant and radical-scavenging activities [3]. Because natural antioxidants often exist together in different combinations in nature, researchers have been investigating the additive and synergistic effects of different antioxidants $[5,6]$.
One such vegetable where a variety of antioxidants can be found is the pepper. Pepper belongs to the genus Capsicum, which is comprised of more than 200 varieties, with Capsicum annuum, Capsicum baccatum, Capsicum chinense, Capsicum frutescens, and Capsicum pubescens being the main five species $[7,8]$. Peppers are consumed worldwide and their importance has increased gradually to place them among the most consumed spice crops in the world [9]. They are usually consumed as food and used as additives in the food industry. They also have a significant role in traditional medicine. In fact, in Indian, Native American, and Chinese traditional medicine, Capsicum species have been used for the treatment of arthritis, rheumatism, stomach aches, skin 
rashes, dog/snake bites, and flesh wounds [10, 11]. These therapeutic applications are related to the capsaicinoid, phenolic compound, and carotenoid content of peppers $[7,12]$.

Carotenoids are the pigments responsible for the yellow, orange, and red color of many types of peppers [13]; however, they are more than mere pigments and play an important role as antioxidants as well. In their capacity as antioxidants, carotenoids protect cells and tissues from harmful radical oxygen species (ROS), acting as scavengers of singlet molecular oxygen [14], peroxyl radicals [15, 16], and reactive nitrogen species (RNS) [17].

It is a well-established fact that free radicals play an important role in pain [18-21]. Pain is "an unpleasant sensory and emotional experience associated with actual or potential tissue damage" while nociception is defined as "the neural processes of encoding and processing noxious stimuli" [22]. Cervero and Laird have proposed that neurophysiological mechanisms responsible for pain can be divided into at least three stages: (a) brief nociceptive stimuli, (b) chronic pain (i.e., inflammatory processes or tissue damage, and (c) abnormal nociceptive perception, such as allodynia and central pain syndrome [23]. Since pain is the most common symptom for which patients seek medical attention and can affect people of any age, gender, or ethnicity $[24,25]$, animal models were created to understand the fundamental biology of pain, including the initiation, continuation, and subsequent termination of the painful signal. In addition, animal tests that use electrical, thermal, mechanical, and chemical stimuli were developed to study nociceptive and anti-inflammatory pain $[26,27]$.

Different botanical compounds gained attention as therapeutic agents that relieve pain and inflammation [28-32]. Among these, carotenoids were assayed for their analgesic and anti-inflammatory effects. Researchers discovered that $\alpha$ - and $\beta$-carotene enhanced the antinociceptive activity of morphine [33], lycopene reduced the thermal hyperalgesia in diabetic mice [34], and lycopene and astaxanthin reduced the levels of the molecules implicated in the inflammation process $[12,35,36]$.

Since carotenoids have potential therapeutic significance in pain and inflammation management and peppers are known to contain carotenoids, we wanted to evaluate the carotenoid content of the guajillo, pasilla, and ancho dried peppers. We also aimed to determine the antioxidant activity of the carotenoids extracted from these peppers and evaluate their analgesic and anti-inflammatory effect using the aceticinduced writhing, hot plate, and carrageenan-induced hind paw oedema tests in mice.

\section{Materials and Methods}

2.1. Plant Material. The three dried pepper varieties were acquired at a local supermarket in Mexico City (Figure 1) The collected plat material was botanically identified and their authenticity was confirmed at the herbarium of the National Medical Center (Centro Medico Nacional) of the Mexican Social Security Institute (Instituto Mexicano del Seguro Social) by MS Abigail Aguilar. The voucher specimens

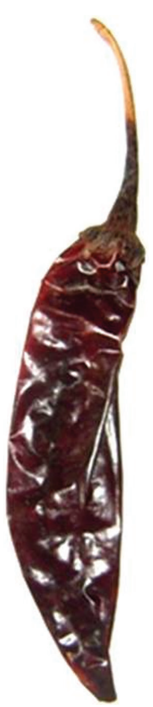

(a)

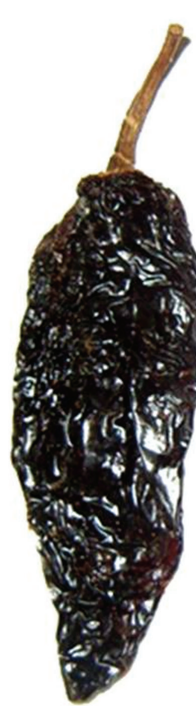

(b)

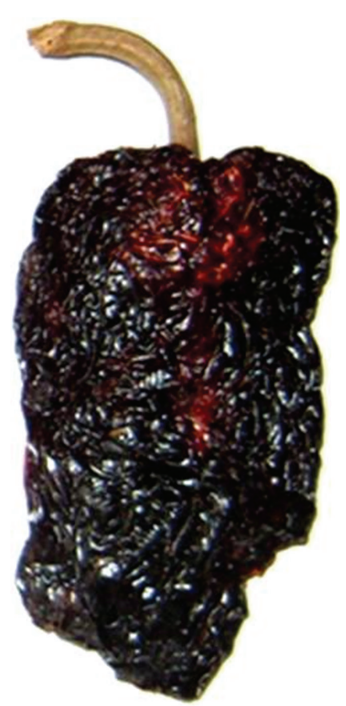

(c)
FIgUre 1: Capsicum annuum L. fruits employed in this study. Guajillo pepper (a), pasilla pepper (b), and ancho pepper (c).

were Guajillo pepper 15660 (Capsicum annuum L.), pasilla pepper 15661 (Capsicum annuum L.), and ancho pepper 15662 (Capsicum annuum L). All of these collections were deposited in the herbarium of the National Medical Center of the Mexican Social Security Institute for future reference.

For powder preparation, peppers were sliced, deseeded, and cut into $1 \mathrm{~cm}^{2}$ pieces. Pepper pieces were then powdered using a Krups GVX211 grinder and passed through no. 100 mesh sieve (150 micron). The powder obtained from each pepper was kept in air-tight plastic bags and protected from light at $4^{\circ} \mathrm{C}$ until pigment extraction.

2.2. Chemicals. Analytical grade acetone, petroleum ether, ethanol, and hexane were acquired from J. T. Baker (BakerMallinckrodt, Mexico), as well as high performance liquid chromatography (HPLC) grade acetonitrile, methanol, tetrahydrofuran, and acetone. DPPH (2,2-diphenyl1 -picrylhydrazyl), $\quad \beta$-carotene, $\beta$-cryptoxanthin, and violaxanthin were obtained from Sigma-Aldrich (St. Louis, MO, USA).

2.3. Pigment Extraction. Extraction of pigments from pepper powder was conducted using the methodology reported previously [37]. Briefly, triplicate samples of $1 \mathrm{~g}$ of pepper powder were ground in a mortar with Hyflo Super Cel (diatomaceous earth) and $20 \mathrm{~mL}$ of cold acetone $\left(5^{\circ} \mathrm{C}\right)$, and then vacuum filtered through a Büchner funnel using no. 4 filter paper that was $10 \mathrm{~cm}$ in diameter (Whatman International Ltd., Maidstone, UK). The filtrate was transferred to a separation funnel together with petroleum ether and water. The two layers were allowed to separate without stirring and the lower phase was discarded. The upper ether layer was washed several times with water to eliminate residual acetone. After the water was removed using anhydrous 
sodium sulfate, the ether phase was transferred to a suitable flask and its volume was adjusted to $10 \mathrm{~mL}$ with petroleum ether. The entire procedure was executed under low light conditions in order to prevent carotenoid degradation.

2.4. Spectrophotometric Analysis of Carotenoids. Total carotenoid content was obtained spectrophotometrically using a method described previously [38]. This method is based on the chromophore properties of carotenoids which allows for grouping in two isochromic families: yellow $\left(C^{Y}\right)$ and red $\left(C^{R}\right)$. Briefly, the petroleum ether extract obtained as described in Section 2.3 was concentrated under nitrogen steam and then dissolved in $10 \mathrm{~mL}$ of acetone. Then, $2 \mathrm{~mL}$ mixture was placed in a $3 \mathrm{~cm}$ cuvette to measure the absorbance using a UV-Vis spectrophotometer (Genesys 10, Thermo Scientific, USA) at 472 and $508 \mathrm{~nm}$. Absorbencies were recorded to obtain both isochromic carotenoid fractions and total carotenoid $\left(C^{T}\right)$ by using the following equations:

$$
\begin{gathered}
C^{Y}=\frac{\left(\left(\mathrm{A}_{472} \times 1724.3\right)-\left(\mathrm{A}_{508} \times 2450.1\right)\right)}{270.9}(\mu \mathrm{g} / \mathrm{mL}), \\
C^{R}=\frac{\left(\left(\mathrm{A}_{508} \times 2144.0\right)-\left(\mathrm{A}_{472} \times 403.3\right)\right)}{270.9}(\mu \mathrm{g} / \mathrm{mL}), \\
C^{T}=C^{R}+C^{Y}(\mu \mathrm{g} / \mathrm{mL}) .
\end{gathered}
$$

2.5. Pigment Identification by Thin-Layer Chromatography. In order to identify the different pigments contained in the extracts obtained from dried peppers, thin-layer chromatography (TLC) was used [39]. For this analysis, pigments were extracted from $2 \mathrm{~g}$ pepper powder as described in Section 2.3. The resulting $10 \mathrm{~mL}$ petroleum ether extract was concentrated using nitrogen steam. The concentrate was then dissolved in $250 \mu \mathrm{L} \mathrm{n}$-hexane. The hexane extract $(20 \mu \mathrm{L})$ was placed on a TLC Silica gel $\mathrm{GF}_{254}$ plate $(20 \mathrm{~cm} \times 20 \mathrm{~cm}$, $0.7 \mathrm{~mm}$, Merck, Darmstadt, Germany) and developed in hexane : petroleum ether : acetone $(1: 2: 1)$. The TLC analysis was repeated four times.

2.6. HPLC Analysis of Pigments. Carotenoid identification in pepper extracts [40] was performed using the Beckman System Gold Liquid Chromatograph HPLC equipment with a model 168 photodiode array detector and the Gold Nouveau V 1.72 Chromatographic Data System (Beckman Coulter, Fullerton, CA, USA). Pigments were extracted from $5 \mathrm{~g}$ of guajillo, pasilla, or ancho pepper powder as described in Section 2.3. The resulting ether phase was concentrated using high purity nitrogen steam and the samples were stored in the freezer protected from light until used for analysis. Each concentrated sample was resuspended in $1 \mathrm{~mL}$ acetone, filtered through a $0.20 \mu \mathrm{m}$ pore nylon membrane, and then injected into a Prodigy 5 ODS column $(25 \mathrm{~cm} \times 4.6 \mathrm{~mm} \mathrm{ID}$, Phenomenex, Torrance, CA, USA) together with an isocratic solvent system of acetonitrile:methanol:tetrahydrofuran (THF) $(58: 35: 7)$ pumped at a flow rate of $1 \mathrm{~mL} / \mathrm{min}$ for the analysis of violaxanthin, $\beta$-cryptoxanthin, and $\beta$-carotene. Visible detection was achieved at $450 \mathrm{~nm}$. The quantification was performed according to a standard curve prepared with commercial $\beta$-carotene, violaxanthin, and $\beta$-cryptoxanthin.

2.7. $\mathrm{DPPH}^{+}$(2,2-Diphenyl-1-Picrylhydrazil) Radical Assay. The $\mathrm{DPPH}^{+}$radical assay was carried out as described by Liu et al., 2008, with a few modifications [5]. The pigments extracted from the pepper powders were tested for their radical scavenging capacity. To initiate the reaction, $0.5 \mathrm{~mL}$ of $0.3 \mathrm{mM} \mathrm{DPPH}^{+}$solution in ethanol: hexane $(1: 1)$ was blended with $1 \mathrm{~mL}$ pigment extract at a concentration of $100 \mu \mathrm{g} / \mathrm{mL}$ in ethanol:hexane $(1: 1)$. The mixture was shaken and incubated at room temperature in the dark for $15 \mathrm{~min}$ and absorbance was measured at $540 \mathrm{~nm}$ with a UV spectrophotometer (Genesys 10 UV, Thermo Scientific, USA). The antioxidant activity of the tested extracts was expressed as

$\%$ Inhibition

$$
=100-\left(\frac{\left(\left(\text { Abs sample }_{\text {sabslank }}\right) \times 100\right)}{\text { Abs }_{\text {control }}}\right),
$$

where $\mathrm{Abs}_{\text {sample }}$ is the absorbance value of pigment extract plus $\mathrm{DPPH}^{+}$solution, Absblank is the absorbance value of pigment extract dissolved in ethanol and hexane, and $\mathrm{Abs}_{\text {control }}$ is the absorbance of the $\mathrm{DPPH}^{+}$solution in ethanol: hexane.

2.8. Animals. Ninety $8-10$-week-old male CD-1 mice with an average weight of $20 \pm 5 \mathrm{~g}$ were obtained from the Autonomous University of Hidalgo State (Universidad Autónoma del Estado de Hidalgo). Animals were maintained in a room at $22 \pm 2^{\circ} \mathrm{C}$ with $12 \mathrm{~h} \mathrm{light/dark} \mathrm{cycle} \mathrm{and} \mathrm{free}$ access to food and water in accordance with the Institutional Animal Research Committee guide for the official Mexican standard [41], regarding the production, care, and use of laboratory animals. Twelve hours before each experiment, animals were fasted, receiving only water, in order to avoid food interference with experimental substance absorption. All studies were approved by the Bioethical Committee of the National School of Biological Sciences.

2.9. Acute Oral Toxicity Assay. Acute oral toxicity assay for the carotenoid extract from guajillo peppers was conducted according to the guidelines OECD no. 423 [42] of the Organization for Economic Cooperation and Development.

2.10. Acetic Acid-Induced Writhing Test. The writhing test was performed following the procedure described previously [43]. Samples were administered to mice intragastrically. Thirty minutes prior to writhing induction, mice were assigned to five different groups of six mice each: group 1 was treated with the vehicle (isotonic saline solution, $0.9 \%$ ), group 2 with ibuprofen as drug reference $(10 \mathrm{mg} / \mathrm{kg}$ body weight), and groups $3-5$ with the carotenoids extracted from 
guajillo peppers at a dose of 5,20 , or $80 \mathrm{mg} / \mathrm{kg}$ body weight. Writhing was induced by intraperitoneal administration of $0.4 \%$ acetic acid. Five minutes after the administration of acetic acid, the number of writhes was counted for $30 \mathrm{~min}$. The percent inhibition of writhing was calculated by using the following formula [44]:

$$
\% \text { Inhibition }=\left(\frac{\text { Mean number of writhes }(\text { control })-\text { Mean number of writhes }(\text { test })}{\text { Mean number of writhes }(\text { control })}\right) \times 100
$$

2.11. Hot Plate Test. The hot plate test was performed following the method of Asongalem et al. [43]. Pain reflex in response to the thermal stimulus was measured using a Le7406 hot plate (Panlab S2, Cornella, Barcelona, Spain). Thirty minutes prior to the test, mice were placed in five different groups of six mice each and were intragastrically treated in the following manner: group 1 was treated with vehicle (isotonic saline solution, $0.9 \%$ ), group 2 with indomethacin as reference drug ( $7 \mathrm{mg} / \mathrm{kg}$ body weight), and groups 3-5 with the carotenoids extracted from guajillo peppers at a dose of 5,20 , or $80 \mathrm{mg} / \mathrm{kg}$ body weight. Mice were placed on a $55 \pm 1^{\circ} \mathrm{C}$ hot plate in order to obtain their response to electrical heat-induced nociceptive pain stimulus judged by the presence of behaviors such as licking of the fore and hind paws or jumping. The pain response was measured at $30 \mathrm{~min}$ and at every hour thereafter for $5 \mathrm{~h}$. The cut-off time used to prevent skin damage was $25 \mathrm{~s}$.

2.12. Carrageenan-Induced Mice Paw Oedema. Paw oedema in mice was induced as described previously [45]. Five groups of mice $(n=6)$ were administered intragastrically with vehicle control (isotonic saline solution), indomethacin as a reference drug $(7 \mathrm{mg} / \mathrm{kg}$ body weight), and carotenoid extract at doses $5,20,80 \mathrm{mg} / \mathrm{kg}$ body weight, $30 \mathrm{~min}$ after carrageenan injection. Acute inflammation was induced by the subplantar administration (in the right paw of the mouse) of $0.1 \mathrm{~mL}$ isotonic saline solution containing $3 \%$ of carrageenan and Tween 80 . The thickness of injected paws was measured before induction of inflammation and at every hour thereafter for $5 \mathrm{~h}$ using a 0.01 -scale micrometer. The inhibitory activity was calculated according the following formula [46]:

$$
\begin{aligned}
\% \text { Inhibition }= & \left(\frac{\left(C_{t}-C_{0}\right)_{\text {control }}-\left(C_{t}-C_{0}\right)_{\text {treated }}}{\left(C_{t}-C_{0}\right)_{\text {control }}}\right) \\
& \times 100,
\end{aligned}
$$

where $C_{t}$ is the paw thickness at time $t, C_{0}$ is the paw thickness before carrageenan injection, $C_{t}-C_{0}$ is thickness of oedema, and $\left(C_{t}-C_{0}\right)_{\text {control }}$ is thickness of oedema after carrageenan injection of control mice at time $t$.

2.13. Data Analysis. Carotenoid content data were reported as mean \pm standard deviation and analgesic and antiinflammation data as mean \pm standard error of the mean (S.E.M). Statistical analyses were conducted using Statistical Package for the Social Sciences (SPSS), version 15 (SPSS Inc.,
Chicago, IL, USA). Data were analyzed by oneway analysis of variance (ANOVA) and differences among the means were compared using Tukey's test for carotenoid content, antioxidant activity, and the writhing test. The Dunnett test was used as a post-hoc test for hot plate and carrageenan assays with a level of significance set at $P<0.05$.

\section{Results and Discussion}

3.1. Guajillo, Pasilla, and Ancho Peppers Have High and Differing Levels of Carotenoids. In order to determine the antioxidant, analgesic, and anti-inflammatory benefits of the guajillo, pasilla, and ancho peppers, we first measured their carotenoid content. A significant difference was observed $(P<0.05)$ in total carotenoid content among the three peppers analyzed (Table 1). Guajillo peppers had the highest carotenoid content followed by pasilla and ancho peppers $(3406 \pm 4,2933 \pm 1$, and $1437 \pm 6 \mu \mathrm{g} / \mathrm{g}$ in dry weight basis (DWB), resp.). Previously, researchers had reported a total carotenoid content of $3721 \mu \mathrm{g} / \mathrm{g}$ in guajillo pepper, $6226 \mu \mathrm{g} / \mathrm{g}$ in pasilla pepper, and $3070 \mu \mathrm{g} / \mathrm{g}$ in ancho pepper [47]. Recently, another study reported guajillo pepper's carotenoid content as $876 \mu \mathrm{g} / \mathrm{g}$ DWB [48]. These differences in carotenoid content among several reports could be due to the differences in genotype, maturity stage, and drying process [47]. According to [49], red paprika pepper has a carotenoid content of $2354 \mu \mathrm{g} / \mathrm{g}$ DWB, which is an amount higher than that of a carrot $(1824 \mu \mathrm{g} / \mathrm{g}$ DWB $)$ and almost equal to that of a tomato $(2047 \mu \mathrm{g} / \mathrm{g}$ DWB). Therefore, despite the varying carotenoid contents reported in the literature, there is mounting evidence to suggest that peppers are also a good source of carotenoids.

Guajillo peppers contained the highest yellow fraction at $1501 \pm 8 \mu \mathrm{g} / \mathrm{g}$ (Table 1). According to [38], the yellow fraction comprised bands with $R_{f}$ (reference front) from 0.96 to 0.69 , including $\beta$-carotene, esterified $\beta$-cryptoxanthin, violaxanthin, antheraxanthin, cucurbitaxanthin, and esterified zeaxanthin, whereas the red fraction comprised bands with $R_{f}$ from 0.37 to 0.20 and included esterified capsanthin and capsorubin. Several groups have demonstrated that the yellow fraction of carotenoids exhibits significant antioxidant activity [50-52].

The pigment extracts from the three peppers analyzed by TLC and HPLC had a complex mixture of carotenoids (Tables 2 and 3). Interestingly, TLC analysis revealed that ancho and pasilla pepper extracts contained green bands associated with chlorophyll content (Figure 2). The carotenoid profile of guajillo peppers identified by TLC was 
TABLE 1: Isochromic fractions (yellow and red) and total carotenoid contents of extracts from dried peppers $(\mu \mathrm{g} / \mathrm{g})$.

\begin{tabular}{lccc}
\hline Peppers & Total carotenoid content $\left(C^{T}\right)$ & Yellow isochromic fraction $\left(C^{Y}\right)$ & Red isochromic fraction $\left(C^{R}\right)$ \\
\hline Guajillo & $3406 \pm 4^{\mathrm{a}}$ & $1501 \pm 8^{\mathrm{a}}$ & $1905 \pm 12^{\mathrm{a}}$ \\
Pasilla & $2933 \pm 1^{\mathrm{b}}$ & $1225 \pm 7^{\mathrm{b}}$ & $1708 \pm 6^{\mathrm{b}}$ \\
Ancho & $1437 \pm 6^{\mathrm{c}}$ & $543 \pm 4^{\mathrm{c}}$ & $894 \pm 10^{\mathrm{c}}$ \\
\hline
\end{tabular}

Results expressed as mean \pm standard deviation, $n=3$. Values followed by different letters (a, b, c) within a column are significantly different (one-way ANOVA, Tukey's post-hoc test, $P \leq 0.05$ ).

TABLE 2: $R_{f}$ of pigments from guajillo, pasilla, and ancho peppers separated by TLC.

\begin{tabular}{lcccc}
\hline Carotenoids & Band color & Guajillo & Pasilla & Ancho \\
& & $R_{f}$ & 0.98 & $R_{f}$ \\
\hline$\beta$-Carotene & Yellow & 0.98 & 0.91 & 0.98 \\
Capsanthin & Red & 0.91 & 0.80 & 0.91 \\
Violaxanthin & Yellow & 0.80 & 0.60 & 0.80 \\
$\beta$-Cryptoxanthin & Yellow & 0.60 & 0.56 & 0.60 \\
Zeaxanthin & Orange & 0.56 & 0.47 & 0.56 \\
Lutein epoxide & Yellow & 0.47 & 0.34 & 0.47 \\
Capsorubin & Yellow & 0.34 & 0.22 & 0.34 \\
Neoxanthin & Orange & 0.22 & 0.22 \\
\hline
\end{tabular}

in agreement with a previous report by Zeb and Murkovic [39].

We found that the contents of violaxanthin, $\beta$-carotene, and $\beta$-cryptoxanthin were significantly different $(P<0.05)$ among the three peppers studied (Table 3 ). Guajillo pepper had the highest $\beta$-carotene and $\beta$-cryptoxanthin content, and pasilla pepper contained the highest amount of violaxanthin. Wall et al. (2001) reported that pasilla peppers contain $539 \pm 63 \mu \mathrm{g} / \mathrm{g} \beta$-carotene, guajillo peppers, $343 \pm 54 \mu \mathrm{g} / \mathrm{g}$, and ancho peppers, $317 \pm 41 \mu \mathrm{g} / \mathrm{g}$. On the other hand, HervertHernández et al. (2010) reported that guajillo peppers contain $73 \mu \mathrm{g} / \mathrm{g} \beta$-carotene and only $20 \mu \mathrm{g} / \mathrm{g} \beta$-cryptoxanthin. Differences among the reported carotenoid contents of these peppers may be due to the differences in genotype, maturity stage, and drying process $[47,48]$.

Since the aim of the study was to evaluate the antioxidant, analgesic, and anti-inflammatory activity of carotenoids, ancho and pasilla pepper extracts were not used in further analyses of analgesia and anti-inflammatory properties due to the presence of chlorophylls in their extracts.

3.2. Guajillo, Pasilla, and Ancho Peppers Have Significantly Different Antioxidant Capacities. We next determined the antioxidant capacity of guajillo, pasilla, and ancho peppers by using the $\mathrm{DPPH}^{+}$scavenging assay. Our results demonstrated that guajillo extracts had a $24.2 \%$ scavenging capacity, which was significantly higher than that of pasilla peppers $(15.6 \%)$ and ancho peppers $(12.3 \%, P<0.05)$. The differences in the antioxidant activity can be attributed to the higher $\beta$ carotene and $\beta$-cryptoxanthin contents of guajillo peppers, since these carotenoids are known to exert significant antioxidant activity $[6,53,54]$.

Researchers have proposed that the types of carotenoids, their concentration, and the ratio at which they are mixed are important variables affecting the antioxidant capacity of an extract $[52,55,56]$. Recently Müller et al. observed that sea buckthorn berry juice had the most complex mixture of carotenoids (lutein, zeaxanthin, $\beta$-cryptoxanthin, $\beta$-carotene, $\alpha$-carotene, and lycopene), which correlated to its high antioxidant activity [6]. In addition, Zanfini et al. reported that the cherry tomato, which had a higher carotenoid content than other tomato varieties, generated the highest antioxidant activity in a $\mathrm{DPPH}^{+}$assay [55]. The function of dietary carotenoids and their metabolites in the human body clearly depends on a wide range of factors beyond the basic chemical properties of these molecules per se [52]; however, our results indicate that the carotenoid extracts from guajillo peppers have high antioxidant activity.

\subsection{Guajillo Pepper Extract Is Not Toxic Even at High} Doses. Guajillo pepper carotenoid extract did not cause any mortality, morbidity symptoms, or other deleterious effects even at the highest dose tested $(2000 \mathrm{mg} / \mathrm{kg}$, intragastrical administration), which indicated a reasonable margin of safety.

\subsection{Guajillo Extract Significantly Reduced Acetic Acid-Induced} Writhing in Mice. Both the carotenoid extract from guajillo pepper administrated at 5,20 , and $80 \mathrm{mg} / \mathrm{kg}$ and $10 \mathrm{mg} / \mathrm{kg}$ ibuprofen significantly reduced the number of writhing episodes induced by acetic acid compared to the control treatment $(P<0.05$, Table 4$)$. The percentage of writhing inhibition was $62.0 \%$ for ibuprofen and 56.4, 47.9, and $43.9 \%$ for carotenoid extracts at 5,20 , and $80 \mathrm{mg} / \mathrm{kg}$, respectively.

Zhu et al. (2011) also reported a similar percentage of inhibition of writhing in mice using 100 and $200 \mathrm{mg} / \mathrm{kg}$ ethanol extract of Desmodium podocarpum, which is a type of shrub used in Chinese folk medicine. Similarly, 
TABLE 3: Carotenoid contents in ancho, guajillo, and pasilla peppers determined by HPLC analysis.

\begin{tabular}{lcccc}
\hline Carotenoid & Retention time $(\mathrm{min})$ & Guajillo pepper & Pasilla pepper & Ancho pepper \\
\hline Violaxanthin & 4.8 & $1671.0 \pm 0.05^{\mathrm{a}}$ & $3667.2 \pm 0.02^{\mathrm{b}}$ & $746.2 \pm 0.05^{\mathrm{c}}$ \\
$\beta$-Cryptoxanthin & 10.7 & $407.2 \pm 0.05^{\mathrm{a}}$ & $212.5 \pm 0.05^{\mathrm{b}}$ & $185.6 \pm 0.01^{\mathrm{c}}$ \\
$\beta$-Carotene & 36.5 & $344.0 \pm 0.05^{\mathrm{a}}$ & $47.7 \pm 0.07^{\mathrm{b}}$ & $220.4 \pm 0.05^{\mathrm{c}}$ \\
\hline
\end{tabular}

Results are expressed in $\mu \mathrm{g} / \mathrm{g}$ DWB (mean $\pm \mathrm{SD}, n=3$ ). Values followed by different letters $(\mathrm{a}, \mathrm{b}, \mathrm{c})$ in the same row are significantly different $(P \leq 0.05$, one way ANOVA, Tukey's post-hoc test).

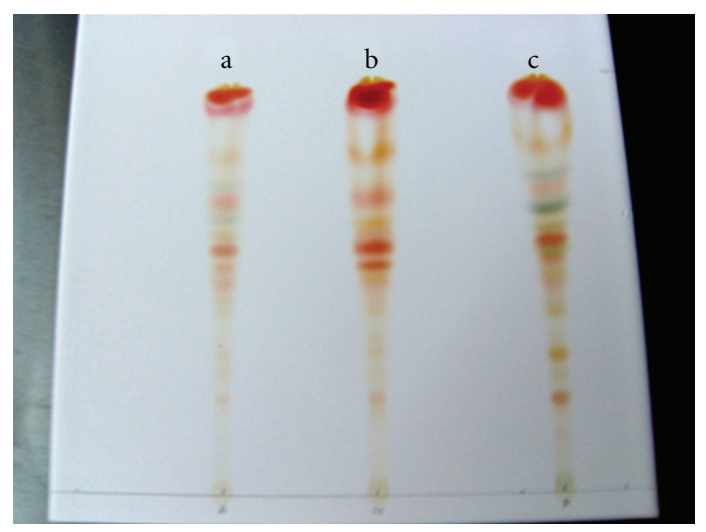

Figure 2: TLC profile of pigments in dried peppers. (a) Ancho pepper, (b) guajillo pepper, (c) pasilla pepper. Ancho and pasilla pepper extracts have green bands, revealing the presence of chlorophylls in these peppers.

Huang et al. (2011) reported 50\% writhing inhibition in mice treated with $1000 \mathrm{mg} / \mathrm{kg}$ of aqueous extract of Xanthii fructus, which is a Chinese seed used in traditional medicine. In addition, Roome et al. (2011) obtained 64\% writhing inhibition with $100 \mathrm{mg} / \mathrm{kg}$ ethyl acetate extract and $84 \%$ with $10 \mathrm{mg} / \mathrm{kg}$ methanol extract from the stems of Aegiceras corniculatum, which is a mangrove plant used in traditional medicine [57-59]. The results of these studies as well as ours suggest that different substances present in seeds, shrubs, and stems of selected plants have analgesic activities similar to the carotenoids extracted with petroleum ether from guajillo peppers.

The acetic acid writhing test is often used to test the nonselective antinociceptive effects of a substance. When animals are intraperitoneally injected with acetic acid, a painful reaction together with acute inflammation emerges in the peritoneal area. The resulting stimulation of peritoneal nociceptors is indirectly caused by the release of endogenous factors, such as algogen, bradykinins, and prostanoids, which stimulate nerve ends $[60,61]$. The analgesic effect of the guajillo pepper carotenoid extract may be due to inhibition of the local prostaglandins. However, further assays are necessary to conclude that the antinociceptive effect of guajillo peppers is due to peripheral analgesia.

\subsection{Guajillo Pepper Extract Prolongs Tactile Heat Tolerance} of Mice. The results of the analgesic effect of the carotenoid extract of guajillo pepper assayed by a hot plate test are shown in Table 5. Guajillo pepper carotenoid extract at the highest dose tested, $80 \mathrm{mg} / \mathrm{kg}$, as well as indomethacin $(7 \mathrm{mg} / \mathrm{kg})$, significantly increased the latency of response compared to the control group $(P<0.05)$. Interestingly, guajillo pepper carotenoid extract had a more prolonged effect than indomethacin, increasing the latency of response time even after $5 \mathrm{~h}$ posttreatment.

The hot plate test is usually used in conjunction with the writhing test to distinguish central nervous system effects from peripheral ones [62]. Our results indicated that $80 \mathrm{mg} / \mathrm{kg}$ guajillo pepper carotenoid extract significantly prolonged the time that mice could endure heat stimuli, suggesting that the antinociceptive effect of the extract was mainly due to the participation of the central nervous system.

There are several recent studies that have demonstrated that pigment extracts from plants and shrubs can exhibit analgesic effects. For example, Mothana et al. (2012) found that $500 \mathrm{mg} / \mathrm{kg}$ methanol extract of Loranthus regularis Steud ex Sprague (a hemiparasitic shrub widely distributed in Yemen and Southern Saudi Arabia) presented a central analgesic effect, which was nearly comparable with that of indomethacin. More recently, Taïwe et al. (2012) reported that a dose of $160 \mathrm{mg} / \mathrm{kg}$ aqueous Crassocephalum bauchiense (Hutch, Asteraceae family, leaves used in traditional medicine in Cameroon) extract caused a marked increase in the latency response in mice during hot plate algesiometer tests for nociception. Similarly, Zhu et al. (2011) reported that the petroleum ether fraction from the ethanol extract of Desmodium podocarpum at a dose of $200 \mathrm{mg} / \mathrm{kg}$ significantly prolonged the latency period of mice compared to the group given distilled water. Moreover, Roome et al. (2011) demonstrated that the ethyl acetate extract from the stems of Aegiceras corniculatum at doses of 10, 25, and $50 \mathrm{mg} / \mathrm{kg}$ caused significant antinociceptive effects. Furthermore, Ashok Kumar et al. (2010) reported that methanol extracts of Amaranthus viridis (A. viridis), A. caudatus, and A. spinosus showed significant pain management effects in albino mice at a dose of $400 \mathrm{mg} / \mathrm{kg}(P<0.01)$, which was attributed to the presence of alkaloids, steroids, flavonoids, terpenoids, and phenolic compounds in these extracts [30, $57,58,63,64]$.

In fact, the antinociceptive effect of many plants has been attributed to their flavonoid [65-67], triterpene [68, 69], or tannin, anthocyanin, alkaloid, and saponin content [70]. Our results suggest that we can add carotenoids of guajillo peppers to the growing list of compounds with antinociceptive activity.

3.6. Anti-Inflammatory Effect of Carotenoid Extract. The guajillo pepper carotenoid extract significantly inhibited 
TABLE 4: The effect of pigments extracted from guajillo pepper on acetic acid-induced writhing test in mice.

\begin{tabular}{lccc}
\hline Treatment & Dose $(\mathrm{mg} / \mathrm{kg})$ & Number of writhes per 30 min & Inhibition $(\%)$ \\
\hline Control & 0 & $71 \pm 2$ & - \\
Ibuprofen & 10 & $27 \pm 9^{\mathrm{a}}$ & 62 \\
Carotenoids & 5 & $34 \pm 6^{\mathrm{a}}$ & 56 \\
extracted from & 20 & $37 \pm 10^{\mathrm{a}}$ & 48 \\
guajillo pepper & 80 & $40 \pm 5^{\mathrm{a}}$ & 44 \\
\hline
\end{tabular}

Results are expressed as mean \pm S.E.M $(n=6)$. ${ }^{\text {a }} \leq \leq 0.05$, statistical significance with respect to control was calculated by one-way ANOVA followed by Tukey's test. Isotonic saline solution was used as the control and ibuprofen as the reference treatment.

TABle 5: Antinociceptive effect of the carotenoid extract from guajillo pepper using a hot plate test on mice.

\begin{tabular}{|c|c|c|c|c|c|c|c|c|c|}
\hline \multirow{3}{*}{ Treatment } & \multirow{3}{*}{ Dose $(\mathrm{mg} / \mathrm{kg})$} & \multicolumn{8}{|c|}{ Latency of response time (s) } \\
\hline & & \multirow{2}{*}{$\begin{array}{l}\text { Before treatment } \\
\qquad 0 \mathrm{~min}\end{array}$} & \multicolumn{7}{|c|}{ After treatment } \\
\hline & & & $30 \mathrm{~min}$ & $60 \mathrm{~min}$ & $120 \mathrm{~min}$ & $180 \mathrm{~min}$ & $240 \mathrm{~min}$ & $300 \mathrm{~min}$ & $360 \mathrm{~min}$ \\
\hline Control & 0 & $5 \pm 0.4$ & $7 \pm 0.4$ & $8 \pm 1$ & $7 \pm 1$ & $9 \pm 1$ & $8 \pm 1$ & $9 \pm 1$ & $8 \pm 1$ \\
\hline Indomethacin & 7 & $5 \pm 1$ & $12 \pm 2^{\mathrm{a}}$ & $12 \pm 1^{\mathrm{a}}$ & $12 \pm 1^{\mathrm{a}}$ & $14 \pm 2^{\mathrm{a}}$ & $13 \pm 1^{\mathrm{a}}$ & $13 \pm 2$ & $12 \pm 2$ \\
\hline \multirow{3}{*}{$\begin{array}{l}\text { Carotenoids extracted } \\
\text { from guajillo pepper }\end{array}$} & 5 & $5 \pm 0.2$ & $9 \pm 1$ & $9 \pm 1$ & $8 \pm 1$ & $11 \pm 2$ & $10 \pm 2$ & $12 \pm 1$ & $10 \pm 1$ \\
\hline & 20 & $5 \pm 1$ & $6 \pm 1$ & $7 \pm 1$ & $10 \pm 1$ & $9 \pm 1$ & $11 \pm 1$ & $10 \pm 1$ & $12 \pm 3$ \\
\hline & 80 & $5 \pm 1$ & $9 \pm 2$ & $10 \pm 2^{\mathrm{a}}$ & $15 \pm 4^{\mathrm{a}}$ & $15 \pm 3^{\mathrm{a}}$ & $15 \pm 3^{\mathrm{a}}$ & $18 \pm 3^{\mathrm{a}}$ & $18 \pm 4^{\mathrm{a}}$ \\
\hline
\end{tabular}

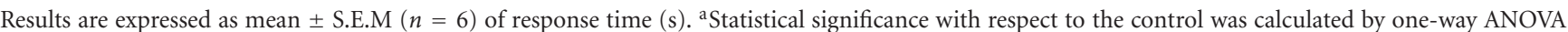
followed by Dunnett's test $(P \leq 0.05)$. Isotonic saline solution was used as the control and indomethacin was used as the reference treatment.

TABLE 6: The effect of carotenoids extracted from dried guajillo pepper on carrageenan-induced paw oedema.

\begin{tabular}{|c|c|c|c|c|c|}
\hline \multirow{2}{*}{ Treatment } & \multirow{2}{*}{ Dose $(\mathrm{mg} / \mathrm{kg})$} & \multirow{2}{*}{ Initial paw size (mm) } & \multicolumn{3}{|c|}{ Paw oedema $(\mathrm{mm})$} \\
\hline & & & $1 \mathrm{~h}$ & $3 \mathrm{~h}$ & $5 \mathrm{~h}$ \\
\hline Control & 0 & $3.0 \pm 0.1$ & $1.5 \pm 0.1$ & $1.7 \pm 0.1$ & $1.9 \pm 0.8$ \\
\hline Indomethacin & 7 & $3.0 \pm 0.1$ & $0.9 \pm 0.2^{\mathrm{a}}$ & $1.1 \pm 0.2^{\mathrm{a}}$ & $0.8 \pm 0.2^{\mathrm{a}}$ \\
\hline \multirow{3}{*}{$\begin{array}{l}\text { Carotenoids extracted } \\
\text { from guajillo pepper }\end{array}$} & 5 & $2.9 \pm 0.1$ & $1.1 \pm 0.2^{\mathrm{a}}$ & $1.1 \pm 0.1^{\mathrm{a}}$ & $0.9 \pm 0.1^{\mathrm{a}}$ \\
\hline & 20 & $2.9 \pm 0.1$ & $1.1 \pm 0.1$ & $1.6 \pm 0.1$ & $1.1 \pm 0.1^{\mathrm{a}}$ \\
\hline & 80 & $3.0 \pm 0.2$ & $1.2 \pm 0.1$ & $1.3 \pm 0.1$ & $1.0 \pm 0.1^{\mathrm{a}}$ \\
\hline
\end{tabular}

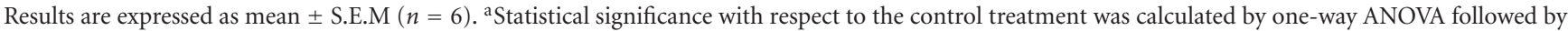
the Dunnett's test $(P \leq 0.05)$. Isotonic saline solution was used as the control and indomethacin was used as the reference treatment.

oedema formation and progression at a dose of $5 \mathrm{mg} / \mathrm{kg}$ compared to the control treatment at 1,3 , and 5 hours after carrageenan injection $(P<0.05$, Table 6$)$. A similar response was obtained with indomethacin compared to the control treatment. Interestingly, at higher doses (20 and $80 \mathrm{mg} / \mathrm{kg}$ ), the guajillo pepper extract significantly reduced oedema generated by the carrageenan at the $5 \mathrm{~h}$ time point $(P<0.05)$.

The carrageenan-induced paw oedema test is suitable for evaluation of anti-inflammatory drugs and assessment of the antioedematous effects of natural products [71]. There are two phases of carrageenan-induced inflammatory reaction: early phase (from 0 to $2.5 \mathrm{~h}$ after injection of carrageenan), which results from the activity of serotonin and bradykinins as well as histamine liberation, and late phase, which is associated with the release of prostaglandins [72].

A large number of studies have indicated that analgesic and anti-inflammatory activities of herbs may be attributed to their natural phenolic components, such as caffeic acid and caffeoylquinic acid, which have antioxidant activities [73]. In fact, Zhu et al. (2011) found that the antiinflammatory activity of Desmodium podocarpum ethanol extract was related to the presence of five major families of compounds in this shrub: phenols, phytosterols, arylpropionic acids, saponins, and enols. In addition, Mothana et al. (2012) concluded that the anti-inflammatory effect of the Loranthus regularis Steud ex Sprague methanol extract was associated with its flavonoid content. Along the same line, Spiller et al. (2008) and Loganayaki et al. (2012) reported that flavonoids and phenolic constituents of Ammannia baccifera L. (a weed that grows in the rice fields in India) exhibited significant anti-inflammatory and analgesic benefits at oral doses of 100 and $200 \mathrm{mg} / \mathrm{kg}$. Importantly, the analgesic effect of the higher dose of this extract $(200 \mathrm{mg} / \mathrm{kg})$ was comparable to standard painkillers, including aspirin and morphine. Moreover, Zimmer et al. (2012) suggested that the antiinflammatory activity of Capsicum baccatum (a red pepper, the most consumed spice in Brazil) may be induced by 
capsaicin. Furthermore, Hosseinzadeh and Younesi (2002) reported that Crocus sativus L (Iridaceae, commonly known as saffron, used in traditional medicine) extracts have acute and/or chronic anti-inflammatory activity, which may be due to their content of flavonoids, tannins, anthocyanins, alkaloids, and saponins [7, 28, 57, 63, 70, 74].

In summary, many plant compounds have antiinflammatory effects. Our results indicate that carotenoids present in the petroleum ether extract from guajillo peppers clearly belong to the group of compounds with significant anti-inflammatory activity.

\section{Conclusions}

The three peppers evaluated in this study are good sources of carotenoids. The carotenoid extract obtained from guajillo peppers exhibited high antioxidant activity, safe margin of toxicity, and significant analgesic and anti-inflammatory benefits. Although our study revealed some possible and novel benefits of the guajillo pepper, future studies are necessary to thoroughly assess the safety of the guajillo carotenoid extract. In addition, further research is necessary to explore the exact antinociceptive and anti-inflammatory mechanism(s) of the guajillo carotenoid extract.

\section{Acknowledgments}

This research was funded by Consejo Nacional de Ciencia y Tecnología (CONACyT) scholarship 202204, Secretaría de Investigación y Posgrado-IPN, Project nos. 20100788 and 20110922 and Comisión de Operación y Fomento Actividades Académicas (COFAA-IPN).

\section{References}

[1] J. A. T. Pennington and R. A. Fisher, "Food component profiles for fruit and vegetable subgroups," Journal of Food Composition and Analysis, vol. 23, no. 5, pp. 411-418, 2010.

[2] V. M. Dembitsky, S. Poovarodom, H. Leontowicz et al., "The multiple nutrition properties of some exotic fruits: biological activity and active metabolites," Food Research International, vol. 44, no. 7, pp. 1671-1701, 2011.

[3] J. F. Ayala-Zavala, V. Vega-Vega, C. Rosas-Domínguez et al., "Agro-industrial potential of exotic fruit byproducts as a source of food additives," Food Research International, vol. 44, no. 7, pp. 1866-1874, 2011.

[4] G. González-Aguilar, R. M. Robles-Sánchez, M. A. MartínezTéllez, G. I. Olivas, E. Alvarez-Parrilla, and L. A. De La Rosa, "Bioactive compounds in fruits: health benefits and effect of storage conditions," Stewart Postharvest Review, vol. 4, no. 3, article 8, pp. 1-10, 2008.

[5] D. Liu, J. Shi, A. Colina Ibarra, Y. Kakuda, and S. Jun Xue, "The scavenging capacity and synergistic effects of lycopene, vitamin $\mathrm{E}$, vitamin $\mathrm{C}$, and $\beta$-carotene mixtures on the $\mathrm{DPPH}$ free radical," LWT_Food Science and Technology, vol. 41, no. 7, pp. 1344-1349, 2008.

[6] L. Müller, K. Fröhlich, and V. Böhm, "Comparative antioxidant activities of carotenoids measured by ferric reducing antioxidant power (FRAP), ABTS bleaching assay ( $\alpha$ TEAC), DPPH assay and peroxyl radical scavenging assay," Food Chemistry, vol. 129, no. 1, pp. 139-148, 2011.
[7] A. R. Zimmer, B. Leonardi, D. Miron, E. Schapoval, J. R. Oliveira, and G. Gosmann, "Antioxidant and antiinflammatory properties of Capsicum baccatum: from traditional use to scientific approach," Journal of Ethnopharmacology, vol. 139, no. 1, pp. 228-233, 2012.

[8] F. Menichini, R. Tundis, M. Bonesi et al., "The influence of fruit ripening on the phytochemical content and biological activity of Capsicum chinense Jacq. cv Habanero," Food Chemistry, vol. 114, no. 2, pp. 553-560, 2009.

[9] D. Bown, ,Encyclopedia of Herbs and Their Uses, Kindersley Dorling, London, Herb Society of America, London, UK, 2001.

[10] M. K. Meghvansi, S. Siddiqui, M. H. Khan et al., "Naga chilli: a potential source of capsaicinoids with broad-spectrum ethnopharmacological applications," Journal of Ethnopharmacology, vol. 132, no. 1, pp. 1-14, 2010.

[11] B. E. V. Wyk and M. Wink, Medicinal Plants of the World: An Illustrated Scientific Guide to Important Medicinal Plants and Their Uses, Timber Press, Portland, Ore, USA, 2004.

[12] J. S. Park, J. H. Chyun, Y. K. Kim, L. L. Line, and B. P. Chew, "Astaxanthin decreased oxidative stress and inflammation and enhanced immune response in humans," Nutrition and Metabolism, vol. 7, no. 1, article 18, 2010.

[13] J. J. Ornelas-Paz, L. A. Cira-Chávez, A. A. Gardea-Béjar et al., "Effect of heat treatment on the content of some bioactive compounds and free radical-scavenging activity in pungent and non-pungent peppers," Food Research International. In press.

[14] P. Di Mascio, S. Kaiser, and H. Sies, "Lycopene as the most efficient biological carotenoid singlet oxygen quencher," Archives of Biochemistry and Biophysics, vol. 274, no. 2, pp. 532-538, 1989.

[15] N. I. Krinsky and K. J. Yeum, "Carotenoid-radical interactions," Biochemical and Biophysical Research Communications, vol. 305, no. 3, pp. 754-760, 2003.

[16] W. Stahl and H. Sies, "Antioxidant activity of carotenoids," Molecular Aspects of Medicine, vol. 24, no. 6, pp. 345-351, 2003.

[17] Y. J. Kim, Y. A. E. Kim, and T. Yokozawa, "Protection against oxidative stress, inflammation, and apoptosis of high-glucoseexposed proximal tubular epithelial cells by astaxanthin," Journal of Agricultural and Food Chemistry, vol. 57, no. 19, pp. 8793-8797, 2009.

[18] D. Salvemini, J. W. Little, T. Doyle, and W. L. Neumann, "Roles of reactive oxygen and nitrogen species in pain," Free Radical Biology and Medicine, vol. 51, no. 5, pp. 951-966, 2011.

[19] H. K. Kim, S. K. Park, J. L. Zhou et al., "Reactive oxygen species (ROS) play an important role in a rat model of neuropathic pain," Pain, vol. 111, no. 1-2, pp. 116-124, 2004.

[20] K. Janes, W. L. Neumann, and D. Salvemini, "Antisuperoxide and anti-peroxynitrite strategies in pain suppression," Biochimica et Biophysica Acta, vol. 1822, no. 5, pp. 815821, 2012.

[21] J. M. Chung, "The role of reactive oxygen species (ROS) in persistent pain," Molecular Interventions, vol. 4, no. 5, pp. 248250, 2004.

[22] J. D. Loeser and R. D. Treede, "The Kyoto protocol of IASP Basic Pain Terminology," Pain, vol. 137, no. 3, pp. 473-477, 2008.

[23] F. Cervero and J. Laird, “One pain or many pains?” Physiology, vol. 6, no. 6, pp. 268-273, 1991.

[24] R. B. Fillingim, C. D. King, M. C. Ribeiro-Dasilva, B. RahimWilliams, and J. L. Riley, "Sex, gender, and pain: a review of 
recent clinical and experimental findings," Journal of Pain, vol. 10, no. 5, pp. 447-485, 2009.

[25] I. Melnikova, "Pain market," Nature Reviews Drug Discovery, vol. 9, no. 8, pp. 589-590, 2010.

[26] M. Barrot, "Tests and models of nociception and pain in rodents," Neuroscience, vol. 211, no. 211, pp. 39-50, 2012.

[27] J. S. Mogil, K. D. Davis, and S. W. Derbyshire, "The necessity of animal models in pain research," Pain, vol. 151, no. 1, pp. $12-17,2010$.

[28] N. Loganayaki, P. Siddhuraju, and S. Manian, "Antioxidant, anti-inflammatory and anti-nociceptive effects of Ammannia baccifera L., a folklore medicinal plant," Journal of Ethnopharmacology, vol. 140, no. 2, pp. 230-233, 2012.

[29] G. G. Garcia, H. F. Miranda, V. Noriega et al., "Antinociception induced by atorvastatin in different pain models," Pharmacology Biochemistry and Behavior, vol. 100, no. 1, pp. 125-129, 2011.

[30] B. S. Ashok Kumar, K. Lakshman, K. N. Jayaveera et al., "Pain management in mice using methanol extracts of three plants belongs to family Amaranthaceae," Asian Pacific Journal of Tropical Medicine, vol. 3, no. 7, pp. 527-530, 2010.

[31] R. A. A. Mothana, M. S. Al-Said, A. J. Al-Rehaily et al., "Antiinflammatory, antinociceptive, antipyretic and antioxidant activities and phenolic constituents from Loranthus regularis Steud. ex Sprague," Food Chemistry, vol. 130, no. 2, pp. 344349, 2012.

[32] Q. Zhao, Y. Zhao, and K. Wang, "Antinociceptive and free radical scavenging activities of alkaloids isolated from Lindera angustifolia Chen," Journal of Ethnopharmacology, vol. 106, no. 3, pp. 408-413, 2006.

[33] N. W. Penn, "Potentiation of morphine analgesic action in mice by $\beta$-carotene," European Journal of Pharmacology, vol. 284, no. 1-2, pp. 191-193, 1995.

[34] A. Kuhad, S. Sharma, and K. Chopra, "Lycopene attenuates thermal hyperalgesia in a diabetic mouse model of neuropathic pain," European Journal of Pain, vol. 12, no. 5, pp. 624632, 2008 .

[35] D. D. Haines, B. Varga, I. Bak et al., "Summative interaction between astaxanthin, Ginkgo biloba extract (EGb761) and vitamin C in Suppression of respiratory inflammation: a comparison with ibuprofen," Phytotherapy Research, vol. 25, no. 1, pp. 128-136, 2011.

[36] M. Hazewindus, G. R. M. M. Haenen, A. R. Weseler, and A. Bast, "The anti-inflammatory effect of lycopene complements the antioxidant action of ascorbic acid and $\alpha$-tocopherol," Food Chemistry, vol. 132, no. 2, pp. 954-958, 2012.

[37] D. B. Rodriguez-Amaya, A Guide to Carotenoid, ILSI Press, Washington, DC, USA, 2001.

[38] D. Hornero-Méndez and M. I. Minguez-Mosquera, "Rapid spectrophotometric determination of red and yellow isochromic carotenoid fractions in paprika and red pepper oleoresins," Journal of Agricultural and Food Chemistry, vol. 49, no. 8, pp. 3584-3588, 2001.

[39] A. Zeb and M. Murkovic, "Thin-layer chromatographic analysis of carotenoids in plant and animal samples," Journal of Planar Chromatography, vol. 23, no. 2, pp. 94-103, 2010.

[40] M. Guerra-vargas, M. E. Jaramillo-flores, L. Dorantes-alvarez, and H. Hernández-sánchez, "Carotenoid retention in canned pickled jalapeño peppers and carrots as affected by sodium chloride, acetic acid, and pasteurization," Journal of Food Science, vol. 66, no. 4, pp. 620-626, 2001.

[41] NOM-062-ZOO-1999, "Especificaciones Técnicas para la produccion, cuidado y uso de los animales de laboratorio,"
Dirección General de Normas, Direccion general de normas, Alcance, México, 1999.

[42] OECD, "Acute oral toxicity—acute toxic class method," Tech. Rep. 423, OECD Publishing, 2001.

[43] E. A. Asongalem, H. S. Foyet, S. Ekobo, T. Dimo, and P. Kamtchouing, "Antiinflammatory, lack of central analgesia and antipyretic properties of Acanthus montanus (Ness) T. Anderson," Journal of Ethnopharmacology, vol. 95, no. 1, pp. 63-68, 2004.

[44] T. Mekonnen, K. Urga, and E. Engidawork, "Evaluation of the diuretic and analgesic activities of the rhizomes of Rumex abyssinicus Jacq in mice," Journal of Ethnopharmacology, vol. 127, no. 2, pp. 433-439, 2010.

[45] R. Marroquin-Segura, M. Flores-Pimentel, R. CarreónSánchez et al., "The effect of the aqueous extract of Helietta parvifolia A. Gray (Rutaceae) stem bark on carrageenaninduced paw oedema and granuloma tissue formation in mice," Journal of Ethnopharmacology, vol. 124, no. 3, pp. 639641, 2009.

[46] O. A. Olajide, S. O. Awe, J. M. Makinde et al., "Studies on the anti-inflammatory, antipyretic and analgesic properties of Alstonia boonei stem bark," Journal of Ethnopharmacology, vol. 71, no. 1-2, pp. 179-186, 2000.

[47] M. M. Wall, C. A. Waddell, and P. W. Bosland, "Variation in $\beta$ carotene and total carotenoid content in fruits of Capsicum," HortScience, vol. 36, no. 4, pp. 746-749, 2001.

[48] D. Hervert-Hernández, S. G. Sáyago-Ayerdi, and I. Goñi, "Bioactive compounds of four hot pepper varieties (Capsicum annuum L.), antioxidant capacity, and intestinal bioaccessibility," Journal of Agricultural and Food Chemistry, vol. 58, no. 6, pp. 3399-3406, 2010.

[49] H. Müller, "Determination of the carotenoid content in selected vegetables and fruit by HPLC and photodiode array detection," Zeitschrift für Lebensmitteluntersuchung undForschung A, vol. 204, no. 2, pp. 88-94, 1997.

[50] A. Mortensen, L. H. Skibsted, J. Sampson, C. Rice-Evans, and S. A. Everett, "Comparative mechanisms and rates of free radical scavenging by carotenoid antioxidants," FEBS Letters, vol. 418, no. 1-2, pp. 91-97, 1997.

[51] N. E. Polyakov, A. I. Kruppa, T. V. Leshina, T. A. Konovalova, and L. D. Kispert, "Carotenoids as antioxidants: spin trapping EPR and optical study," Free Radical Biology and Medicine, vol. 31, no. 1, pp. 43-52, 2001.

[52] A. J. Young and G. M. Lowe, "Antioxidant and prooxidant properties of carotenoids," Archives of Biochemistry and Biophysics, vol. 385, no. 1, pp. 20-27, 2001.

[53] V. Böhm, N. L. Puspitasari-Nienaber, M. G. Ferruzzi, and S. J. Schwartz, "Trolox equivalent antioxidant capacity of different geometrical isomers of $\alpha$-carotene, $\beta$-carotene, lycopene, and zeaxanthin," Journal of Agricultural and Food Chemistry, vol. 50, no. 1, pp. 221-226, 2002.

[54] N. J. Miller, J. Sampson, L. P. Candeias, P. M. Bramley, and C. A. Rice-Evans, "Antioxidant activities of carotenes and xanthophylls," FEBS Letters, vol. 384, no. 3, pp. 240-242, 1996.

[55] A. Zanfini, G. Corbini, C. La Rosa, and E. Dreassi, "Antioxidant activity of tomato lipophilic extracts and interactions between carotenoids and $\alpha$-tocopherol in synthetic mixtures," LWT_Food Science and Technology, vol. 43, no. 1, pp. 67-72, 2010.

[56] L. H. Skibsted, "Carotenoids in antioxidant networks. Colorants or radical scavengers," Journal of Agricultural and Food Chemistry, vol. 60, no. 10, pp. 2409-2417, 2012. 
[57] Z. Z. Zhu, K. J. Ma, X. Ran et al., "Analgesic, anti-inflammatory and antipyretic activities of the petroleum ether fraction from the ethanol extract of Desmodium podocarpum," Journal of Ethnopharmacology, vol. 133, no. 3, pp. 1126-1131, 2011.

[58] T. Roome, A. Dar, S. Naqvi, and M. I. Choudhary, "Evaluation of antinociceptive effect of Aegiceras corniculatum stems extracts and its possible mechanism of action in rodents," Journal of Ethnopharmacology, vol. 135, no. 2, pp. 351-358, 2011.

[59] M. H. Huang, B. S. Wang, C. S. Chiu et al., "Antioxidant, antinociceptive, and anti-inflammatory activities of Xanthii Fructus extract," Journal of Ethnopharmacology, vol. 135, no. 2, pp. 545-552, 2011.

[60] P. S. V. Satyanarayana, N. K. Jain, A. Singh, and S. K. Kulkarni, "Isobolographic analysis of interaction between cyclooxygenase inhibitors and tramadol in acetic acid-induced writhing in mice," Progress in Neuro-Psychopharmacology and Biological Psychiatry, vol. 28, no. 4, pp. 641-649, 2004.

[61] H. Matsumoto, H. Naraba, A. Ueno et al., "Induction of cyclooxygenase-2 causes an enhancement of writhing response in mice," European Journal of Pharmacology, vol. 352, no. 1, pp. 47-52, 1998.

[62] K. Srinivasan, S. Muruganandan, J. Lal et al., "Antinociceptive and antipyretic activities of Pongamia pinnata leaves," Phytotherapy Research, vol. 17, no. 3, pp. 259-264, 2003.

[63] R. A. A. Mothana, M. S. Al-Said, A. J. Al-Rehaily et al., "Antiinflammatory, antinociceptive, antipyretic and antioxidant activities and phenolic constituents from Loranthus regularis Steud. ex Sprague," Food Chemistry, vol. 130, no. 2, pp. 344349, 2012.

[64] G. S. Taïwe, E. N. Bum, E. Talla et al., "Evaluation of antinociceptive effects of Crassocephalum bauchiense Hutch (Asteraceae) leaf extract in rodents," Journal of Ethnopharmacology, vol. 141, no. 1, pp. 234-241, 2012.

[65] V. García-Mediavilla, I. Crespo, P. S. Collado et al., "The anti-inflammatory flavones quercetin and kaempferol cause inhibition of inducible nitric oxide synthase, cyclooxygenase2 and reactive C-protein, and down-regulation of the nuclear factor kappaB pathway in Chang Liver cells," European Journal of Pharmacology, vol. 557, no. 2-3, pp. 221-229, 2007.

[66] F. Sharififar, G. Dehghn-Nudeh, and M. Mirtajaldini, "Major flavonoids with antioxidant activity from Teucrium polium L.," Food Chemistry, vol. 112, no. 4, pp. 885-888, 2009.

[67] R. González, I. Ballester, R. López-Posadas et al., "Effects of flavonoids and other polyphenols on inflammation," Critical Reviews in Food Science and Nutrition, vol. 51, no. 4, pp. 331362, 2011.

[68] R. A. A. Mothana, S. S. Hasson, W. Schultze, A. Mowitz, and U. Lindequist, "Phytochemical composition and in vitro antimicrobial and antioxidant activities of essential oils of three endemic Soqotraen Boswellia species," Food Chemistry, vol. 126, no. 3, pp. 1149-1154, 2011.

[69] H. P. T. Ammon, "Boswellic acids in chronic inflammatory diseases," Planta Medica, vol. 72, no. 12, pp. 1100-1116, 2006.

[70] H. Hosseinzadeh and H. M. Younesi, "Antinociceptive and anti-inflammatory effects of Crocus sativus L. stigma and petal extracts in mice," BMC Pharmacology, vol. 2, no. 1, article 7, 2002.

[71] A. Basu and A. K. N. Chaudhuri, "Preliminary studies on the antiinflammatory and analgesic activities of Calotropis procera root extract," Journal of Ethnopharmacology, vol. 31, no. 3, pp. 319-324, 1991.

[72] P. Antonisamy and S. Ignacimuthu, "Immunomodulatory, analgesic and antipyretic effects of violacein isolated from Chromobacterium violaceum," Phytomedicine, vol. 17, no. 3-4, pp. 300-304, 2010.

[73] T. Han, H. L. Li, Q. Y. Zhang et al., "Bioactivity-guided fractionation for anti-inflammatory and analgesic properties and constituents of Xanthium strumarium L.," Phytomedicine, vol. 14, no. 12, pp. 825-829, 2007.

[74] F. Spiller, M. K. Alves, S. M. Vieira et al., "Anti-inflammatory effects of red pepper (Capsicum baccatum) on carrageenanand antigen-induced inflammation," Journal of Pharmacy and Pharmacology, vol. 60, no. 4, pp. 473-478, 2008. 

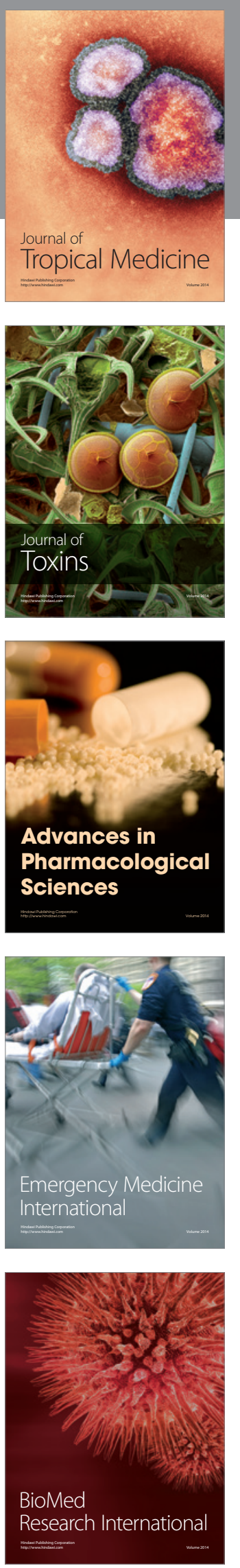
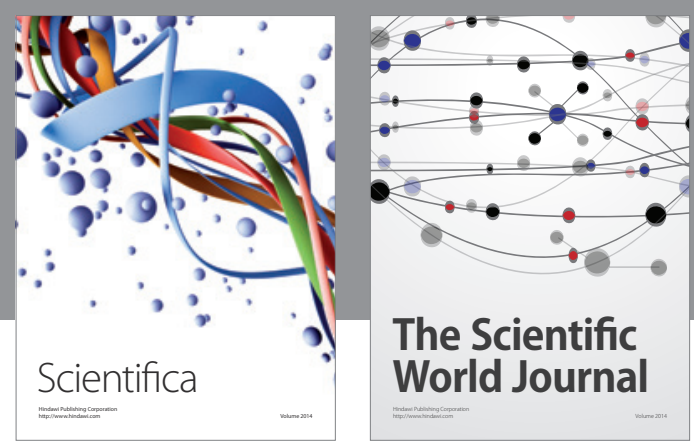

The Scientific World Journal
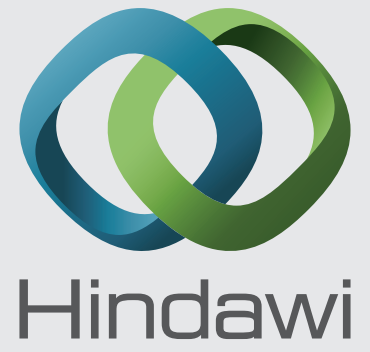

Submit your manuscripts at

http://www.hindawi.com
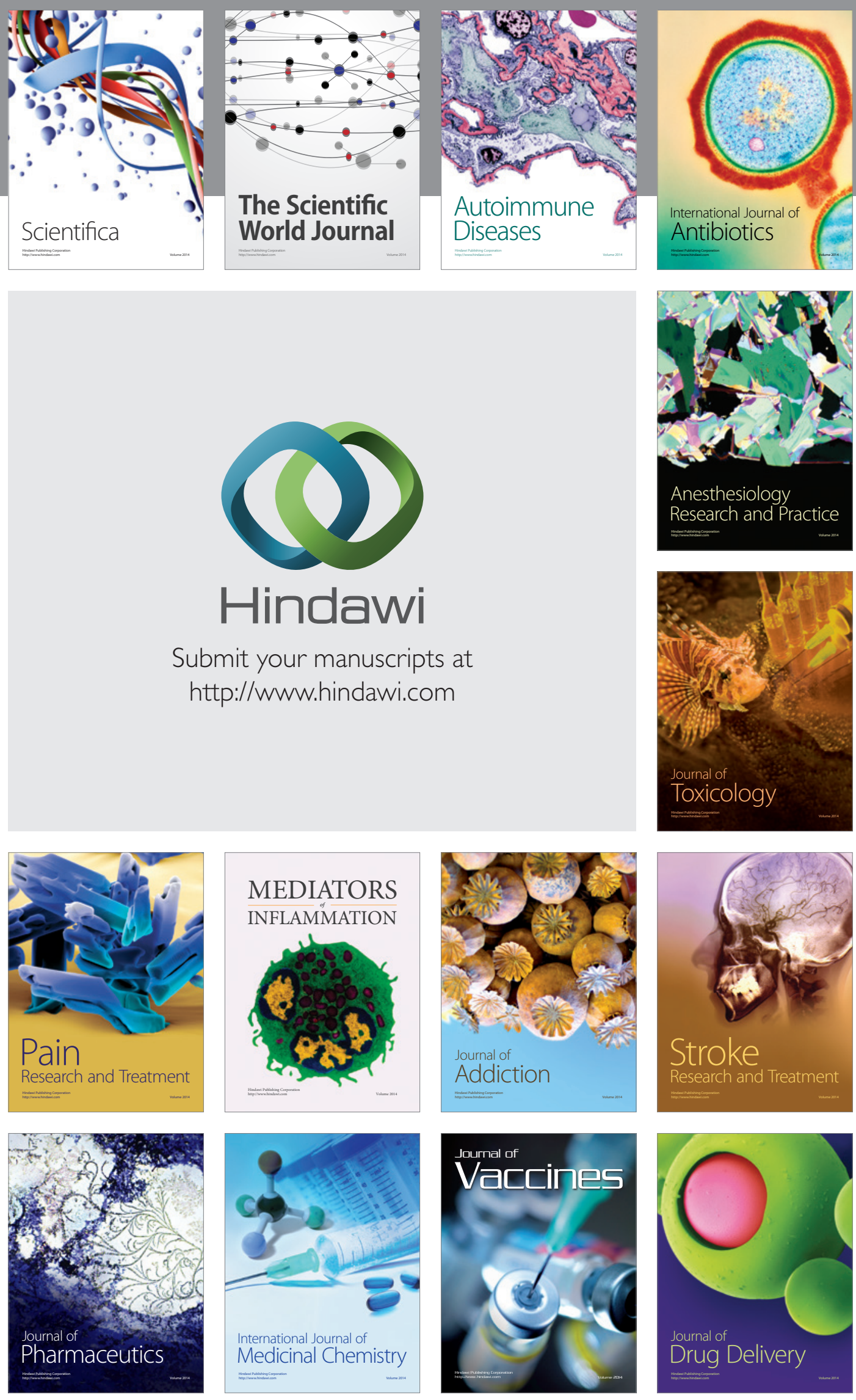